\title{
Primary resistance to clarithromycin, metronidazole and amoxicillin of Helicobacter pylori isolated from Tunisian patients with peptic ulcers and gastritis: a prospective multicentre study
}

Khansa Ben Mansour ${ }^{1 *}$, Christophe Burucoa ${ }^{2}$, Meriem Zribi ${ }^{1}$, Afef Masmoudi ${ }^{1}$, Sami Karoui ${ }^{3}$, Lamia Kallel ${ }^{3}$, Soufiène Chouaib ${ }^{4}$, Samira Matri ${ }^{3}$, Monia Fekih ${ }^{3}$, Sonia Zarrouk ${ }^{5}$, Mounir Labbene, Jalel Boubaker ${ }^{3}$, Imed Cheikh , Mongi Ben Hriz ${ }^{6}$, Nadia Siala ${ }^{6}$, Abdelkarim Ayadi ${ }^{7}$, Azza Filali ${ }^{3}$, Nabil Ben Mami ${ }^{4}$, Taoufik Najjar ${ }^{8}$, Ahmed Maherzi ${ }^{6}$, Mohamed Tahar Sfar ${ }^{7}$, Chedlia Fendri ${ }^{1}$

\begin{abstract}
Background: The frequency of primary resistance to antibiotics in $\mathrm{H}$. pylori isolates is increasing worldwide. In Tunisia, there are limited data regarding the pattern of $\mathrm{H}$. pylori antibiotic primary resistance.

Aim: To evaluate the primary resistance of $\mathrm{H}$. pylori to clarithromycin, metronidazole and amoxicillin and to detect the mutations involved in clarithromycin resistance.

Materials and methods: 273 strains isolated from adults and children were enrolled. The primary resistance to clarithromycin, metronidazole and amoxicillin was evaluated by means of E-test minimal inhibitory concentration (MIC). The real-time PCR using Scorpion primers was performed in all cases to assess clarithromycin primary resistance and point mutations involved.

Results: No resistance to amoxicillin was detected. For adults, resistance to clarithromycin and metronidazole was found respectively in $14.6 \%$ and $56.8 \%$, and respectively in $18.8 \%$ and $25 \%$ in children. Overall, the rates of global primary resistance to clarithromycin and metronidazole in Tunisia were respectively determined in $15.4 \%$ and $51.3 \%$. By the use of Scorpion PCR, the A2143G was the most frequent point mutation observed (88.1\%), followed by the A2142G (11.9\%); the A2142C was not found and 18 of 42 patients (42.8\%) were infected by both the resistant and the susceptible genotype.

The association of clarithromycin resistance with gender was not statistically significant, but metronidazole resistant strains were isolated more frequently in females (67.8\%) than in males (32.2\%) and the difference was significant. As for gastroduodenal diseases, the difference between strains isolated from patients with peptic ulceration and those with non peptic ulceration was not statistically significant. When about the distribution of resistant strains to clarithromycin and metronidazole between the three Tunisian cities (Tunis, Menzel Bourguiba and Mahdia), the difference was not statistically significant.
\end{abstract}

Conclusion: Local data regarding the primary resistance of $\mathrm{H}$. pylori to clarithromycin, metronidazole and amoxicillin and the main genetic mutation involved in clarithromycin resistance in vivo (A2143G) are necessary to prove a clear need for a periodic evaluation of antibiotic consumption and new therapeutic strategies in Tunisia in order to avoid the emergence of resistant strains.

\footnotetext{
* Correspondence: bmkhansa@gmail.com

${ }^{1}$ Microbiology laboratory/UR04SP08 Rabta University Hospital-Tunis, $1007 \mathrm{El}$ Jabbari, Tunisia

Full list of author information is available at the end of the article
} 


\section{Introduction}

Helicobacter pylori (H. pylori) colonizes the human stomach and it has emerged as an important pathogen in the field of gastroenterology [1]. In Tunisia, his prevalence is average $90 \%$ in peptic ulcer [2]. Since 2005, the Tunisian consensus had recommended the eradication of H. pylori by a triple therapy which includes amoxicillin, clarithromycin or metronidazole combined with proton pump inhibitors (PPI) for 7 to 10 days [3]. Resistance to these drugs reduces the success rate of treatment regimens both in adults and children. Several studies have demonstrated that primary resistance to clarithromycin is a major predictive factor for therapeutic failure [4]; the mechanism of this resistance decreased binding of the antibiotic to the $50 \mathrm{~S}$ ribosomal subunit of the microorganism and is due to three distinct point mutations (A2142G, A2143G and A2142C) within the peptidyltransferase region encoded in domain $\mathrm{V}$ of the H. pylori bacterial $23 \mathrm{~S}$ rRNA gene [5]. The detection of mutations was performed by the use of several real-time PCR methods [5-9]. Resistance to metronidazole is mainly due to mutations in the $r d x A$ gene encoding RdxA, an oxygeninsensitive nitroreductase [10]. When about primary resistance to metronidazole, conflicting results have been reported on its impact in the treatment outcome [11]. Prevalence rates of primary clarithromycine and metronidazole resistance were documented to be higher in developing countries than in industrialized ones [12,13]. Because of limited data on the resistance of H. pylori to antibiotics in Tunisia, the aims of the present prospective and multicentre study were: (i) to evaluate, by means of E-test and Scorpion PCR the prevalence of primary resistance to clarithromycin, and by means of E-test, the rates of primary resistance to metronidazole and amoxicillin of 273 clinical strains isolated from children and adults, (ii) to detect, for the first time in Tunisia, the mutations involved in clarithromycin resistance by Scorpion PCR as previously described [14].

\section{Materials and methods Materials \\ Patients and biopsies}

In this study, the biopsy samples were taken over a 2 years-period (March 2005 to August 2007) from patients referred for endoscopy at 6 different units of gastroenterology in three Tunisian cities (Tunis, Menzel Bourguiba and Mahdia). 273 patients had H. pylori positive culture; 48 children (aged from 2 to 14 years; mean age 8.75 years) were distributed into gastritis in 47 cases and one case of duodenal ulcer and, 225 adults (aged from 18 to 88 years; mean age 38.3 years) in which 148 cases were defined as gastritis, 66 cases as duodenal ulcer and gastric ulcer was observed in 11 cases. All patients had not been treated before. Regarding the total group, patients were distributed into gastritis in 195 cases, duodenal ulcer in 67 cases and gastric ulcer in 11 cases. The biopsy specimens were cultured on Columbia agar plates supplemented with 10\% horse blood and Skirrow supplement (Oxoid, England) under microaerobic conditions for a maximum of 6 days as described by Ben Mansour et al [15].

\section{Setting}

6 gastroenterology centers in 3 Tunisian cities: $1 /$ Tunis (Adult Units A and B in Rabta University Hospital, Adult Gastroenterology Unit-Charles-Nicolle University Hospital, and Paediatric Unit in Mongi-Slim University Hospital); 2/Adult Gastroenterology Unit-Menzel Bourguiba Regional Hospital, and 3/Paediatric Unit-Mahdia Regional Hospital, between March 2005 and August 2007.

\section{DNA extraction}

Genomic DNA was extracted with the QIAamp DNA mini kit (Qiagen, Germany) according to the manufacturer's instructions. The isolated DNA was eluted in 200 $\mu \mathrm{l}$ of $1 \times \mathrm{TE}$ buffer $(10 \mathrm{mM}$ Tris- $\mathrm{HCl}, 1 \mathrm{mM}$ EDTA $[\mathrm{pH} 8.0])$ and stored at $-20^{\circ} \mathrm{C}$ until use.

\section{MIC determination}

The inoculum was adjusted to an opacity equivalent to a 3-4 McFarland turbidity standard and was flooded on Columbia agar plates containing $10 \%$ horse blood. The E-test strip (AB Biodisk, Sweden) was placed on the plate when it was dry and according to the instructions of the manufacturer. Incubation was performed in a microaerobic atmosphere for 48 to 72 hours at $37^{\circ} \mathrm{C}$. Strains were considered resistant to clarithromycin when the MIC was $\geq 1 \mu \mathrm{g} / \mathrm{ml}$ for clarithromycin, $\geq 8$ $\mu \mathrm{g} / \mathrm{ml}$ for metronidazole and $\geq 0.5 \mu \mathrm{g} / \mathrm{ml}$ for amoxicillin. These breakpoints were used on the basis of recommendations as previously described [16].

Determination of point mutations in the $23 \mathrm{~S}$ rRNA gene of H. pylori by Scorpion PCR

A 140-bp fragment of the $23 \mathrm{~S}$ rRNA gene of 273 strains of $H$. pylori was amplified by using primer 23SF2 and scorpion primers (Table 1). By using the Smart Cycler 2.0 thermocycler, the PCR and hybridization reactions were carried out in a volume of $25 \mu \mathrm{l}$ with the Premix Ex Taq (TAKARA, Shiga, Japan), $1 \mu$ l of extracted DNA from culture (approximately $200 \mathrm{ng}$ ), 0,1 $\mu \mathrm{M}$ of primer 23SF2, $0,14 \mu \mathrm{M}$ of 23Ssc A2142G, 0,18 $\mu \mathrm{M}$ of 23Ssc A2143G, 0,1 $\mu \mathrm{M}$ of 23Ssc A2142C and $0,08 \mu \mathrm{M}$ of $23 \mathrm{Ssc}$ WT. Amplification was performed after a denaturation step $\left(95^{\circ} \mathrm{C}\right.$ for $\left.15 \mathrm{~s}\right)$ for 50 cycles, annealing $\left(55^{\circ} \mathrm{C}\right.$ for $\left.30 \mathrm{~s}\right)$ and extension $\left(72^{\circ} \mathrm{C}\right.$ for $\left.20 \mathrm{~s}\right)$. Four channels were reading the fluorescence for each sample: 6-carboxyfluorescein [FAM], Texas red, Cy3 and $\mathrm{Cy} 5$. Data analysis was performed with Cepheid 
Table 1 Scorpion primers and primer sequences

\begin{tabular}{|c|c|c|}
\hline Oligonucleotide & Mutations & Sequence \\
\hline 23SF2 & - & 5'-TGCGAAATTCCTTGTCGG-3' \\
\hline $23 S S C$ & WT & $\begin{array}{l}\text { 5'-FAM AAGGTAGGTGAAAATTCCTCC } \\
\text { TACC BHQ1 HEG GGACCACGGGGTCTIT-3' }\end{array}$ \\
\hline $23 \mathrm{Ssc}$ & A2143G & $\begin{array}{l}\text { 5'-Texas red AAGGTAGGTGAAAATTCCTCC } \\
\text { TACC BHQ2 HEG GGACCACGGGGTCTTT-3' }\end{array}$ \\
\hline $23 S s c$ & A2142G & $\begin{array}{l}\text { 5'-Cy3 AAGGTAGGTGAAAATTCCTCC } \\
\text { TACC BHQ1 HEG GGACCACGGGGTCTTC-3' }\end{array}$ \\
\hline $23 \mathrm{Ssc}$ & A2142C & $\begin{array}{l}\text { 5'-Cy5 AAGGTAGGTGAAAATTCCTCC } \\
\text { TACC BHQ1 HEG GGACCACGGGGTCTTG-3' }\end{array}$ \\
\hline
\end{tabular}

Software (Cepheid, Sunny vale, CA). Four strains of $H$. pylori were used as positive controls: one reference strain (J99) with the wild type genotype/phenotype and three Clarithromycin-resistant strains (HP 825, HP 225 and HP 222) with mutations determined by sequencing of the $23 \mathrm{~S}$ rRNA gene (mutations A2142C, A2142G and A2143G, respectively) [14].

\section{Statistical analysis}

Data were analyzed using $X^{2}$ test. A $p$ value of $<0.05$ was considered to be statistically significant.

\section{Results}

\section{Detection of resistance to clarithromycin, metronidazole} and amoxicillin by E-test

In adults, the rates of primary resistance to clarithromycin and metronidazole were determined respectively in $14.6 \%(33 / 225)$ and $56.8 \%$ (128/225) (Table 2). Primary resistance to both clarithromycin and metronidazole was found in $12.9 \%(29 / 225)$ of cases.

Among children, the primary resistance to clarithromycin and to metronidazole was found respectively in 9 cases $(18.8 \%)$ and in 12 cases (25\%) of all 48 isolates (Table 2). 8 strains (16.7\%) were resistant to both clarithromycin and metronidazole.

Overall, the rates of global primary resistance to clarithromycin and metronidazole in Tunisia were respectively determined in $15.4 \%$ (42 of 273 ) and in $51.3 \%$ $(140 / 273)$ and the rate of primary resistance to both clarithromycin and metronidazole resistance was $13.6 \%$
$(37 / 273)$ in all studied strains. No resistance to amoxicillin was found in the present study.

\section{Detection of clarithromycin resistance and point} mutations conferring resistance to clarithromycin by Scorpion PCR

In the present study, the primary resistance to clarithromycin was also determined by means of Scorpion PCR as reported elsewhere [14]. Resistance rate was 18.8\% (9/48) among children and $14.6 \%(33 / 225)$ in adults. We have not found discrepancies between Scorpion PCR and E-test methods. Mutations detected in only 42 clarithromycinresistant strains were summarized in Table 3 . In 37 out of the 42 studied strains, A2143G was detected (88.1\%), with $21.4 \%(8 / 37)$ in children and $78.6 \%(29 / 37)$ in adults. The A2142G was found in $11.9 \%$ (5/42) of strains; $2.3 \%$ was detected in children and $9.6 \%$ in adults. The prevalence of the two point mutations (A2143G and A2142G) did not statistically differ between adults and children. The A2142C mutation was not found in the present study and was also less common. By using Scorpion PCR, we revealed a presence of a mixed population in the same sample. Interestingly, 18 of 42 subjects (42.8\%) were infected by both the susceptible and the resistant genotype.

The distribution of primary resistance to clarithromycin and metronidazole according to gender and gastroduodenal diseases was shown in tables 4 and 5 . As for association of clarithromycin resistance with gender, no significant difference in resistance was found ( $\mathrm{p}>0.05$ ). In contrast to clarithromycin, metronidazole resistant

Table 2 Distribution of resistant strains to clarithromycin, metronidazole and amoxicillin among children, adults and a total group

\begin{tabular}{|c|c|c|c|c|c|}
\hline & Clarithromycin Resistance & $\begin{array}{l}\text { Clarithromycin } \\
\text { Susceptible }\end{array}$ & $\begin{array}{l}\text { Metronidazole } \\
\text { Resistance }\end{array}$ & $\begin{array}{c}\text { Metronidazole } \\
\text { Susceptible }\end{array}$ & $\begin{array}{l}\text { Amoxicilline } \\
\text { Resistance }\end{array}$ \\
\hline $\begin{array}{l}\text { Children } \\
(\mathrm{N}=48)\end{array}$ & $\begin{array}{c}9 \\
(18.8 \%)\end{array}$ & $\begin{array}{c}39 \\
(81.2 \%)\end{array}$ & $\begin{array}{c}12^{*} \\
(25 \%)\end{array}$ & $\begin{array}{c}36 \\
(75 \%)\end{array}$ & 0 \\
\hline $\begin{array}{l}\text { Adults } \\
(\mathrm{N}=225)\end{array}$ & $\begin{array}{c}33 \\
(14.6 \%)\end{array}$ & $\begin{array}{c}192 \\
(85.4 \%)\end{array}$ & $\begin{array}{c}128^{*} \\
(56.8 \%)\end{array}$ & $\begin{array}{c}97 \\
(43.2 \%)\end{array}$ & 0 \\
\hline $\begin{array}{l}\text { Total group } \\
(\mathrm{N}=273)\end{array}$ & $\begin{array}{c}42 \\
(15.4 \%)\end{array}$ & $\begin{array}{c}231 \\
(84.6 \%)\end{array}$ & $\begin{array}{c}140 \\
(51.3 \%)\end{array}$ & $\begin{array}{c}133 \\
(48.7 \%)\end{array}$ & 0 \\
\hline
\end{tabular}

\footnotetext{
*: a significant difference is present
} 
Table 3 Relationship between mutations conferring clarithromycin resistance and pathologies

\begin{tabular}{cccc}
\hline & NPU* $^{*}$ & PU** $^{* *}$ & Total \\
\hline A2143G & $28(75.6 \%)$ & $9(24.4 \%)$ & 37 \\
A2142G & $4(80 \%)$ & $1(20 \%)$ & 5 \\
A2142C & 0 & 0 & 0 \\
\hline
\end{tabular}

$\mathrm{NPU}^{*}$ : non peptic ulceration; $\mathrm{PU}^{* *}$ : peptic ulceration

strains were isolated more frequently in females than in males (67.8\% vs. $32.2 \%)$ and the difference was statistically significant $(\mathrm{p}<0.05)$.

When about gastroduodenal diseases, no statistically difference was found between strains isolated from patients having peptic ulceration and those with non peptic ulceration ( $\mathrm{p}>0.05)$.

As for the distribution of resistant strains to clarithromycin and metronidazole among the 3 Tunisian cities (Table 6), the difference was not statistically significant.

\section{Discussion}

In Tunisia, it's very important to know the rates of primary resistance of $H$. pylori strains to clarithromycin, metronidazole and amoxicillin, especially when antibiotic resistance in $H$. pylori represents a serious public health problem.

In adults, the rates of primary resistance to clarithromycin and metronidazole were documented as $17.5 \%$ for clarithromycin and 56\% for metronidazole in 2002 [16]. There is a decrease in the rate of clarithromycin resistance with $14.6 \%$ founded in our present study and a slightly variation (56.8\%) among metronidazole. In terms of clarithromycin primary resistance, our prevalence would seem higher than that computed in Malaysia (2.1\%) [17], in Germany (2.2\%) [18], in Canada (less than 4\%) [19], in Hong-Kong (4.5\%) [20], in Korea (5-6\%) [21] and in one European multicentre study (9.9\%) [11]. This prevalence was almost similar to those found in the USA (10-15\%) [22], in France [23] but was lower to that detected in Iran (17\%) [24], in Turkish (27.6\%) [25] and in one European study (43.5\%) [26]. This difference in clarithromycin resistance rate between several countries might be due to the prescription and administration of this antibiotic. Indeed, since clarithromycin is a widely used antimicrobial drug to treat infection in other organ systems than gastric tract, e.g.,

Table 4 Relationship between the sex of patients and resistance rates

\begin{tabular}{lccc}
\hline & Female & Male & Total \\
\hline Clarithromycin resistance & $26(61.9 \%)$ & $16(38.1 \%)$ & 42 \\
Metronidazole resistance & $95(67.8 \%)^{*}$ & $45(32.2 \%)^{*}$ & 140 \\
\hline *. a significant difference is present & &
\end{tabular}

Table 5 Relationship between the gastroduodenal diseases and resistance rates

\begin{tabular}{lccc}
\hline & NPU & PU & Total \\
\hline Clarithromycin resistance & $32(76.2 \%)^{* *}$ & $10(23.8 \%)^{* *}$ & 42 \\
Metronidazole resistance & $96(68.6 \%)^{* *}$ & $44(31.4 \%)^{* *}$ & 140 \\
\hline
\end{tabular}

**: the difference was not statistically significant

respiratory tract infections, the prevalence of clarithromycin-resistant $H$. pylori is increasing continuously. No differences in gastroduodenal diseases were seen between patients with non peptic ulceration and those with peptic ulceration ( $\mathrm{p}>0.05$ ); the majority of studies have mentioned no differences in prevalence in accordance with disease status, but two studies did mention such differences, and they concluded that duodenal ulcer and non-ulcer dyspepsia patients should be managed differently in medical practice and considered independently in eradication trials [27]. A2143G and A2142G are the most prevalent point mutations, and studies have claimed that these mutations play a major role in clarithromycin resistance $[5,23]$. The prevalence distribution of A2143G (78.6\%) and A2142G (9.6\%) in adults was similar to those of patients in Taiwan study and in a prospective multicentre survey carried out in Europe [26]. We have not found the A2142C mutation which is less common, e.g., it was found in 5 of 129 resistant strains [5].

As for metronidazole resistance, it is well known that the prevalence of $H$. pylori is much higher in developing countries (50-80\%). Our prevalence was much higher than that documented in an European multicentre study and in Bulgaria where the rates were evaluated respectively to $33.1 \%$ and $26.5 \%[11,28]$, but was lower to that computed in Columbia (82\%) [29], in Mexico (76.3\%) [30] and in Sweden (76\%) [31]. In one Indian study, the resistance to metronidazole was evaluated to $41.9 \%$ [32]. When regarding risk factors, we showed a higher primary metronidazole resistance in female patients compared with male ones, most likely due to the wide use of imidazoles for gynaecological infection. In agreement with data presented by Glupczynski et al and Batnavala et al, metronidazole resistant isolates were found significantly more frequently in females than in males and in nonEuropean natives than in subjects born in European

Table 6 Resistance rates among the 3 Tunisian cities

\begin{tabular}{ccccc}
\hline & $\begin{array}{c}\text { Tunis } \\
\mathbf{( N =} \\
\mathbf{1 8 1})\end{array}$ & $\begin{array}{c}\text { Menzel } \\
\text { Bourguiba } \\
(\mathbf{N}=\mathbf{8 3})\end{array}$ & $\begin{array}{c}\text { Mahdia } \\
(\mathbf{N}=\mathbf{9})\end{array}$ & $\begin{array}{c}\text { Total } \\
\mathbf{( N =}\end{array}$ \\
\hline $\begin{array}{c}\text { Clarithromycin } \\
\text { resistance } \\
\begin{array}{c}\text { Metronidazole } \\
\text { resistance }\end{array}\end{array}$ & $27^{* *}$ & $12^{* *}$ & 3 & 42 \\
\hline
\end{tabular}

**: the difference was not statistically significant 
countries $[33,34]$. The same cause was explained by Koletzko et al in their study where they found that metronidazole was widely used in Africa and Asia to treat parasitic diseases and gynaecological infections [35].

For children, the prevalence of clarithromycin primary resistance $(18.8 \%)$ was in agreement with a French one where resistance to clarithromycin was detected in $18 \%$ [36], and slightly lower than those founded in a European prospective multicentre study and in Spain study where the rates were evaluated respectively to $20 \%$ and $21.1 \%$ $[35,37]$, but more lower than that documented in an Argentinean study (29.1\%) [38]. Our prevalence was lower than that reported by one previous Tunisian study conducted with 46 treated children, where the susceptibility testing was performed in 10 cases and where the rates of resistance to clarithromycin and metronidazole were respectively $30 \%$ and $90 \%$ [39].

When regarding the point mutations conferring resistance to clarithromycin, we found that A2143G was dominant followed by A2142G mutation, the A2142C was not detected. Domingo et al [40] and Pina et al [9] showed that the A2143G was more prevalent. De Francesco et al [41] reported that the A2143G was prevalent in their study and concluded that this mutation reduces markedly the eradication therapy efficacy. As for metronidazole resistance, our prevalence $(25 \%)$ was much higher than that reported in 105 untreated children in Bulgaria (16.2\%) [30], but was slightly higher than that documented from children in Argentina (23.9\%), in Spain (23\%) [37] and in a European study (23\%) [35].

Overall, the resistance rate for clarithromycin was lower in adults than in children (14.6\% vs. $18.8 \%)$, which points to an acquisition of the resistance during childhood. Indeed, macrolides are very often used nowadays to treat respiratory infections in young children. By contrast, for metronidazole the resistance rate was markedly higher in adults than in children (56.8\% vs. $25 \%)$. Our results were not in agreement with those founded in a European study [35], where the rates were very similar in adults and children and where they concluded that the similar rate was in favour of transmission of a resistant strain to the children mostly from their mothers who widely used metronidazole to treat gynaecologic infections. In contrast to clarithromycin and metronidazole, no amoxicillin resistance was observed; this finding was similar to those determined by Kim et al [21] and Wolle et al [18] in their studies. This is despite the wide use of this antibiotic, both alone and combined with clavulanic acid for the treatment of respiratory tract infections or $H$. pylori infection in children and adults. However, resistance to amoxicillin has appeared in some countries with low frequencies and could increase. The determination of resistant strains to antibiotics by the E-test method has proven clinically reliable except in the case of metronidazole for which the E-test has a tendency to overestimate the presence of resistance. The reason is not known, but it may be that a pre-incubation of the media in an anaerobic atmosphere has been shown a factor that increasing metronidazole activity [42]. For that reason and for the lack of clinicobacteriological correlation, the Maastricht III 2005 Consensus Report discourages routine metronidazole susceptibility testing [43]. Then, further standardization should be performed regarding the medium, the inoculum and the growth atmosphere.

In conclusion, we believe that the widespread use of macrolides in our country for the treatment of upper respiratory tract infections could have an undesirable outcome in the emergence of clarithromycin resistant strains of $H$. pylori, reducing the success of therapy rate. Moreover, the rate of annual consumption of antibiotics in Tunisia was evaluated to $4 \%$ which is a risk factor for increasing resistant strains to antibiotics; when regarding macrolides, for example, the rate of consumption in Tunisia exceed 4 millions units per year [44]. The clarithromycin resistance decreases the effectiveness of antibiotic therapy and is the main risk factor for treatment failure: resistance reduces the efficacy of the first line therapy by up to $70 \%$ [24]. Among the Maastricht III consensus report [43], treatment should achieve an eradication rate of $\geq 80 \%$. The threshold of clarithromycin resistance at which this antibiotic should not be used, or a clarithromycin susceptibility test should be performed, is $15-20 \%[43,45]$. In Tunisia, physicians can continue the prescription of clarithromycin as a treatment for $H$. pylori infection in adults, in whom $14.6 \%$ of strains are resistant to this antibiotic, but in our paediatric population where the rate of this resistance was $18.8 \%$, clarithromycin should not be used. Our study is the first to show that A2143G is the main genetic mutation involved in $H$. pylori clarithromycin resistance in vivo, thus suggesting that new therapeutic strategies are needed. When about metronidazole, we think that physicians might well refrain from using this antibiotic in order to prevent the emergence of more resistant strains especially because of the high rate of metronidazole resistant strains in Tunisia. In one study performed in North India, Bhatia et al [32] have concluded that imidazole-based eradication regimens should be abandoned in North India regardless of in vitro susceptibility results (41.9\%).

Because of the emergence of resistant strains in our country, there is a clear need for a periodic evaluation of antibiotic consumption, particularly of clarithromycin in public hospitals and in private clinical sector.

There are no competing interests to declare for this study. 


\section{Author details}

${ }^{1}$ Microbiology laboratory/UR04SP08 Rabta University Hospital-Tunis, $1007 \mathrm{El}$ Jabbari, Tunisia. ${ }^{2}$ EA 4331 « Laboratoire Inflammation Tissus Epithéliaux Cytokines », 86021 Poitiers, France. ${ }^{3}$ Gastroenterology A unit, Rabta University Hospital-Tunis, 1007 El Jabbari, Tunisia. ${ }^{4}$ Gastroenterology B unit, Rabta University Hospital-Tunis, 1007 El Jabbari, Tunisia. ${ }^{5}$ Gastroenterology unit, Regional hospital of Menzel Bourguiba, 7050, Tunisia. ${ }^{6}$ Pediatric unit Mongi Slim University Hospital, La Marsa, 2070 Tunis, Tunisia. ${ }^{7}$ Pediatric unit, Mahdia Regional Hospital, 5100, Tunisia. ${ }^{8}$ Gastroenterology unit, Charles Nicolle University Hospital, Bd 9Avril, 1006 Bab Souika, Tunis, Tunisia.

\section{Authors' contributions}

BMK was responsible for the collection of biopsies, H. pylori conventional culture, had carried out the molecular genetic studies, performed the statistical analysis, drafted the manuscript and participated in the design of the study. ZM and MA were participated in the design of the study. $\mathrm{KS}, \mathrm{KL}$, $C S, M S, F M, Z S, L M, B J, C l, B H M, S N, A A, F A, B M N, N T, M A$ and SMT were helped to the constitution of $H$. pylori strains collection, $B C$ had helped to molecular genetic studies. Finally, FC had conceived of the study, participated in its design and coordination and helped to draft the manuscript. All authors have read and approved the final manuscript.

\section{Competing interests}

There are no competing interests to declare for this study.

All enrolled patients were consent to take part in our research.

This prospective multicentre study was performed in Microbiology

laboratory-Rabta University Hospital, Tunis, Tunisia in research unit UR04SP08.

Received: 9 June 2010 Accepted: 13 August 2010

Published: 13 August 2010

\section{References}

1. Solerman A, Perren A, Schmid S, Eigenmann F, Guller R, Weher KB, Meier F, Eichenberger P, Komminoth P: Assesment of Helicobacter pylori clarithromycin resistance mutations in archival gastric biopsy samples. Swiss Med Wkly 2005, 135:327-332

2. Dimel N, Khamassi S, Bouzaïdi S, Labbene M, Ben Ammar A, Fendri C, Arrouji Z, Ben Jilani S, Zermani R: Prevalence of Helicobacter pylori in Tunisia: in asymptomatic controls and in none ulcerous dyspepsia and in duodenal ulcer: a prospective study of 183 cases. Tunis Med 1995, 73:373-377.

3. Consensus: Actualisation du consensus du traitement de la maladie ulcéreuse gastro-duodénale non compliquée de l'adulte en Tunisie. Journal Officiel de la République Tunisienne Ministère de la santé publique 2006, Avril-Mai.

4. Murakami K, Sato R, Okimoto T, Nasu M, Fujioka T, Kodama M, Kagawa J, Sato $\mathrm{S}$, Abe H, Arita T: Eradication rates of clarithromycin-resistant Helicobacter pylori using either rabeprazole or lansoprazole plus amoxicillin and clarithromycin. Aliment Pharmacol Ther 2002, 16:1933-8

5. Versalovic J, Shortridge D, Kibler K, Griffy MV, Beyer J, Flamm RK, Tanaka SK, Graham DY, Go MF: Mutations in 23 S rRNA are associated with clarithromycin resistance in Helicobacter pylori. Antimicrob Agents Chemother 1996, 40:477-480.

6. Gibson JR, Saunders NA, Burke B, Owen RJ: Novel method for rapid determination of calrithromycin sensitivity in Helicobacter pylori. J Clin Microbiol 1999, 37:3746-3748

7. Marais A, Monteiro L, Occhialini A, Pina M, Lamouliatte $H$, Mégraud F: Direct detection of Helicobacter pylori resistance to macrolides by a polymerase chain reaction/DNA enzyme immunoassay in gastric biopsy specimens. Gut 1999, 44:463-467.

8. Occhialini A, Urdaci M, Doucet-Populaire F, Bébéar CM, Lamouliatte H, Mégraud F: Macrolides resistance in Helicobacter pylori : rapid detection of point mutations and assays of macrolides binding to ribosomes. Antimicrob Agents Chemother 1997, 41:2724-2728.

9. Pina M, Occhialini A, Monteiro L, Doermann HP, Mégraud F: Detection of point mutations associated with resistance of Helicobacter pylori to clarithromycin by hybridization in liquid phase. J Clin Microbiol 1998 36:3285-3290.

10. Goodwin A, Kersulyte D, Sisson G, Veldhuyzen van Zanten SJ, Berg DE Hoffman PS: Metronidazole resistance in Helicobacter pylori is due to null mutations in a gene ( $\mathrm{rdxA}$ ) that encodes an oxygen-insensitive NADPH nitroreductase. Mol Microbiol 1998, 28:383-393.
11. Lerang F, Moum B, Haug JB, Tolås P, Breder O, Aubert E, Høie O, Søberg T, Flaaten $B$, Farup $P$, Berge $T$ : Highly effective twice-daily triple therapies for Helicobacter pylori infection and peptic ulcer disease: does in vitro metronidazole resistance have any clinical relevance? Am J Gastroenterol 1997, 92:248-53.

12. Osato MS, Reddy R, Graham DY: Metronidazole and clarithromycin resistance amongst Helicobacter pylori isolates from a large metropolitan hospital in the United States. Int J Antimicrob Agents 1999, 12:341-7.

13. Glupczynski Y, Megraud F, Lopez-Brea M, Andersen LP: European multicentre survey of in vitro antimicrobial resistance in Helicobacter pylori. Eur J Clin Microbiol Infect Dis 2001, 20:820-3.

14. Burucoa C, Garnier M, Silvain C, Fauchère JL: Quadruplex real-time PCR assay using allele-specific scorpion primers for detection of mutations conferring clarithromycin resistance to Helicobacter pylori. J Clin Microbiol 2008, 46:2320-2326.

15. Ben Mansour K, Fendri C, Zribi M, Masmoudi A, Labbene M, Fillali A, Ben Mami N, Najjar T, Meherzi A, Sfar T, Burucoa C: Prevalence of Helicobacter pylori vacA, cagA, iceA and oipA genotypes in Tunisian patients. Annals of Clinical Microbiology and Antimicrobials 2010, 9(10):1-7.

16. Chaabouni $H$, Bouzid H, Masmoudi A, Cheikh I, Fendri C, Ben Ammar A: Evaluation in vitro de la résistance primaire de Helicobacter pylori aux antibiotiques chez les maladies souffrant d'ulcère duodénal en Tunisie. Gastroenterol Clin Biol 2004, 28:A135.

17. Norazah A, Zakaria WR, Abdullah SA, Mohamed R: Characterization of clarithromycin resistance in Malaysian isolates of Helicobacter pylori. World J Gastroenterol 2009, 15:3161-3165.

18. Wolle K, Leodolter A, Malfertheiner P, König W: Antibiotic susceptibility of Helicobacter pylori in Germany: stable primary resistance from 1995 to 2000. J Med Microbiol 2002, 51:705-709.

19. Fellone CA: Epidemiology of the antibiotic resistance of Helicobacter pylori in Canada. Can J Gastroenterol 2000, 14:879-882.

20. Ling TKW, Leung WK, Lee CC, Ng EK, Yung MY, Chung MY, Chung SS, Sung JJ, Cheng AF: The antimicrobial susceptibility of Helicobacter pylori in Hong Kong (1997-2001). Helicobacter 2002, 7:327-329.

21. Kim JJ, Reddy R, Lee M, Kim JG, El-Zaatari FA, Osato MS, Graham DY, Kwon DH: Analysis of metronidazole, clarithromycin and tetracycline resistance of Helicobacter pylori isolates form Korea. J Antimicrob Chemother 2001, 47:459-461.

22. Laine L, Fennerty MB, Osato M, Sugg J, Suchower L, Probst P, Levine JG Esomeprazole-based Helicobacter pylori eradication therapy and the effect of antibiotic resistance: results of three US multicenter, doubleblind trials. Am J Gastroenterol 2000, 95:3393-3398.

23. Mégraud F: H.pylori antibiotic resistance: prevalence, importance, and advances in testing. Gut 2004, 53:1374-1384.

24. Mohammedi M, Doroud D, Massarrat S, Farahvach MJ: Clarithromycin resistance in Iranian Helicobacter pylori strains before introduction of clarithromycin. Helicobater 2003, 8:79-80.

25. Baglan PH, Bozdayi G, Ozkan M, Ahmed K, Bozdayi AM, Ozden A Clarithromycin resistance prevalence and iceA gene status in Helicobacter pylori clinical isolates in Turkish patients with duodenal ulcer and functional dyspepsia. J Microbiol 2006, 44:409-416.

26. van Doorn LJ, Glupczynski Y, Kusters JG, Megraud R, Midolo P, MaggiSoloca N, Quiroz DMM, Nouhan N, Stet E, Quint WGV: Accurate prediction of macrolide resistance in Helicobacter pylori by a PCR line probe assay for detection of mutations in the $23 \mathrm{~S}$ rRNA gene: multicenter validation study. Antimicrob Agent Chemother 2001, 45:1500-1504.

27. Broutet $\mathrm{N}$, Tchamgoué $\mathrm{S}$, Pereira $\mathrm{E}$, Lamouliatte $\mathrm{H}$, Salamon $\mathrm{R}$, Mégraud $\mathrm{F}$ : Risk factors for failure of Helicobacter pylori therapy-results of individual data analysis of 2751 patients. Aliment Pharmacol Ther 2003, 17:99-109.

28. Boyanova L: Prevalence of multidrug-resistant Helicobacter pylori in Bulgaria. J Med Microbiol 2009, 58:930-935.

29. Alvarez A, Moncayo Jl, Santacruz JJ, Santacoloma M, Corredor LF, Reinosa E: Antimicrobial Susceptibility and Mutations Involved in Clarithromycin Resistance in Helicobacter pylori Isolates from Patients in the Western Central Region of Columbia. Antimicrob Agent Chemother 2009, 53:4022-4024.

30. Torres J, Camorlinga-Ponce M, Perez-Perez G, Madrazo-De La Garza, Dehesa M, Conza'lez-Valencia G, Munoz O: Increasing multidrug resistance in Helicobacter pylori strains isolated from children and adults in Mexico. J Clin Microbiol 2001, 39:2677-2680. 
31. Wheeldon TU, Granstrom M, Hoang TT, Phuncarg DC, Nilsson LE, Sorberg M: The importance of the level of metronidazole resistance for the success of Helicobacter pylori eradication. Aliment Pharmacol Ther 2004, 19(12):1315-1321.

32. Bhatia V, Ahuja V, Das B, Bal C, Sharma MP: Use of imidazole-based eradication regimens for Helicobacter pylori should be abandoned in North India regardless of in vitro antibiotic sensitivity. J Gastroenterol Hepathol 2004, 19(6):619-625.

33. Glupczynski Y: European Multicentre Study Group on Antibiotic Susceptibility of Helicobacter pylori. Results of a multicentre European survey in 1991 of metronidazole resistance in Helicobacter pylori. Eur J Clin Microbiol Infect Dis 1992, 11:777-781.

34. Batnavala N, Bavies GR, Abdi Y, Clements L, Rampton DS, Hardie JM: High prevalence of Helicobacter pylori metronidazole resistance in migrants to east London: relation with previous nitroimidazole exposure and gastroduodénale disease. Gut 1994, 35:1562-1566.

35. Koletzko S, Richy F, Bontems P, Crone J, Kalach N, Monteiro ML, Gottrand F, Celinska-Cedro D, Roma-Giannikou E, Orderda G, Kolacek S, Urruzuno P, Martinez-Gomez MJ, Casswall T, Ashorn M, Bodanszky H, Mégraud F: Prospective multicentre study on antibiotic resistance of Helicobacter pylori strains obtained from children living in Europe. Gut 2006, 55:1711-1716.

36. Kalach N, Benhamou PH, Campeotto F, Bergeret M, Dupont C, Raymond J: Clarithromycin Resistance and Eradication of Helicobacter pylori in Children. Antimicrob Agent Chemother 2001, 45:2134-2135.

37. Lopez-Brea M, Martinez MJ, Domingo D, Alarcon T: A 9 year study of clarithromycin and metronidazole resistance in Helicobacter pylori from Spanish children. J Antimicrob Chemother 2001, 48:295-297.

38. Alarcon T, Vega AE, Domingo D, Martinez MJ, Lopez-Brea M: Clarithromycin resistance among Helicobacter pylori strains isolated from children: prevalence and study of mechanism of resistance by PCR-Restriction Fragment Length Polymorphism analysis. J Clin Microbiol 2003, 41:486-488,

39. Mrad S, Boukthir S, Fdhila F, Fendri C, Barsaoui S: Children helicobacter pylori infection: antibiogram results. Tunis Med 2005, 83:599-602.

40. Domingo D, Alarcon T, Sanz JC, Sanchez I, Lopez-Brea M: High frequency of mutations at position 2144 of $23 \mathrm{~S}$ rRNA gene in clarithromycinresistant Helicobacter pylori strains isolated in Spain. J Antimicrob Chemother 1998, 41:573-574.

41. De FrancescoV, Zullo A, lerardi E, Giorgio F, Perna F, Hassan C, Morini S, Panella C, Vaira D: Phenotypic and genotypic Helicobacter pylori clarithromycin resistance and therapeutic outcome: benefits and limits. $J$ Antimicrobiol Chemother 2010, 65:327-332.

42. Cederbrant $G$, Kahlmeter $G$, Ljungh A: Proposed mechanism for metronidazole resistance in Helicobacter pylori. J Antimicrob Chemother 1992, 29:115-120.

43. Malfertheiner P, Mégraud F, O'Morain C, Bazzoli F, El-Omar E, Graham D, Hunt R, Rokkas T, Vakil N, Kuipers EJ: Current concepts in the management of Helicobacter pylori infection: the Maastricht III Consensus Report. Gut 2007.

44. Zouiten F, Ben Rachid A, Neifer N: About antibiotic consumption in Tunisia. Tunis Med 1999, 77:467-471.

45. Delchier JC: Quelles recommandations pour le management de l'infection à Helicobacter pylori après la troisième conférence de consensus européenne (Maastricht III) ? Gastroenterol Clin Biol 2006, 30:1361-1364.

doi:10.1186/1476-0711-9-22

Cite this article as: Ben Mansour et al:: Primary resistance to clarithromycin, metronidazole and amoxicillin of Helicobacter pylori isolated from Tunisian patients with peptic ulcers and gastritis: a prospective multicentre study. Annals of Clinical Microbiology and Antimicrobials 2010 9:22.

\section{Submit your next manuscript to BioMed Central and take full advantage of:}

- Convenient online submission

- Thorough peer review

- No space constraints or color figure charges

- Immediate publication on acceptance

- Inclusion in PubMed, CAS, Scopus and Google Scholar

- Research which is freely available for redistribution

Submit your manuscript at www.biomedcentral.com/submit
Biomed Central 